Situs Jurnal : $\underline{\text { http://ejournal.stiepancasetia.ac.id/index.php/jieb }}$

Jilid 5 Nomor 3 November 2019

Hal $409-414$

\title{
HUBUNGAN FAKTOR FINANSIAL DENGAN PRESTASI KERJA KARYAWAN PADA BANK KALSEL
}

\section{Zaid Abdurrakhman*}

Abstract: Social factors on employee work performance can be identified regarding whether there is a significant relationship between financial factors and the work performance of Bank Kalimantan Selatan employees. The research objective is to find out the significant relationship between financial factors and the work performance of Bank Kalimantan Selatan employees. To prove the bivariate variable relationship is tested by t test which measures the significance of whether or not the independent variables partially on work performance. It turns out that based on the results of data processing through SPSS with financial factor $t$ test has a significant level with Y below 0.05 and found $t$ count with a significant level of 0.0299 Thus it can be said that financial factors have a significant relationship with work performance.

Keywords: financial factor and work performance

Abstrak: Faktor sosial terhadap prestasi kerja karyawan dapat diidentifikasi menyangkut apakah terdapat hubungan yang signifikan antara factor financial dengan prestasi kerja karyawan bank kalsel. Tujuan penelitian yang ingin dicapai adalah untuk mengetahui hubungan yang signifikan antara factor financial dengan prestasi kerja karyawan bank kalsel. Untuk membuktikan hubungan variable secara bivariate dilakukan pengujian dengan uji t yang mengukur signifikan tidaknya variable bebas secara parsial terhadap prestasi kerja. Ternyata berdasarkan hasil olah data melalui SPSS dengan uji t factor finansial memiliki level signifikan dengan Y dibawah 0.05 dan ditemukan t hitung dengan level signifikan sebesar 0.0299 Dengan demikian dapatlah dikatakan bahwa faktor finansial memiliki hubungan yang signifikan dengan prestasi kerja.

Kata kunci: faktor finansial dan prestasi kerja

\section{Latar Belakang}

Perekonomian Nasional dewasa ini sedang berusaha untuk mengurangi dampak yang kurang menguntungkan dari situasi dan kondisi kelesuan ekonomi, dengan jalan menumbuhkan produktivitas Nasional dan potensi dalam Negara antara lain dengan mengembangkan sebesar mungkin pendapatan non migas dan menciptakan Sumber daya manusia yang berkualitas. Sebagai persiapan memasuki era informasi komunikasi dan teknologi yang menuntut persaingan disegala bidang.

Salah satu aspek pembangunan dibidang Ekonomi dipengaruhi oleh adanya kesiapan Sumber daya manusia yang dalam pelaksanaannya tidak terlepas dari perkembangan teknologi. Dengan banyak perusahaan berdiri, maka dengan sendirinya lapangan pekerjaan adanya peningkatan, akan tetapi membawa berbagai masalah terutama pada kondisi kerja. Hal yang demikian disebabkan belum siapnya tenaga kerja untuk menerima perkembangan teknologi tersebut dengan berbagai masalah yang ditimbulkan. Keadaan yang demikian dinilai kurangnya motif / dorongan pendidikan dan ketrampilan yang dimiliki, ditambah lagi dengan factor 
melimpahnya tenaga kerja yang menyebabkan kurangnya perhatian dari perusahaan terhadap kondisi kerja. Pembangunan dunia kerja yang serba kompleks dan bersifat lintas sektoral memerlukan upaya penanganan dan penanggulangan masalah Sumber daya manusia yang bersifat konsepsional dan terpadu.

Disamping itu perkembangan teknologi yang mencakup semua bidang telah menimbulkan perubahan-perubahan baik dari segi metode kerja, penanggulangan masalah ketenaga kerjaan tersebut, khususnya dalam pengembangan Sumber daya manusia perlu adanya kebijaksanaan terhadap peningkatan tenaga kerja yang berkualitas dan produktif. Pada dasarnya setiap perusahaan akan selalu berusaha agar semangat dan gairah kerja dari karyawannya dapat ditingkatkan. Untuk itu perhatian dan penilaian terhadap prestasi kerja mereka sangat dibutuhkan, karena sebagai indikator dalam melakukan suatu pekerjaan yang lebih baik oleh setiap karyawannya agar mempunyai moral kerja yang tinggi.

Bila suatu perusahaan menempatkan karyawannya pada posisi/ tempat yang tepat, maka aktivitas perusahaan juga akan berjalan secara efisien dan menimbulkan kepuasan /keharmonisan kedua belah pihak dalam melaksanakan tugasnya. Hal tersebut memang beralasan, sebab kalau penempatan tenaga kerja didasarkan atas pertimbangkan tertentu bukan atas dasar rasio yang objektif sehingga tidak sesuai dengan skill yang dimiliki, maka karyawan akan merasa berat/terbebani dengan tugas-tugas yang kurang mampu untuk dikerjakan. Dengan demikian akan timbul suatu penurunan semangat dan kreativitas kerja yang pada akhirnya akan merugikan pihak perusahaan yang bersangkutan.

Seiring dengan lajunya pertumbuhan ekonomi pada abad ke 21 ini mendorong perusahaan berupaya untuk menciptakan suatu strategi meningkatkan kinerja karyawannya. Harus kita akui bahwa penilaian prestasi kerja pada karyawan merupakan bagian penting dari seluruh proses karyawan yang bersangkutan.

Pentingnya penilaian prestasi kerja yang rasional dan diterapkan secara objektif terlihat paling sedikit dua kepentingan yaitu : Kepentingan karyawan yang bersangkutan sendiri dan kepentingan perusahaan (Bank Kalsel). seperti:

Bagi para karyawan prestasi kerja berperan sebagai umpan balik tentang berbagai hal

1. Kemampuan

2. Pelatihan

3. Kekurangan dan potensinya yang pada gilirannya bermanfaat untuk menentukan tujuan, rencana dan pengembangan kariernya, bahkan ada menumbuhkan loyalitas dan kepuasan kerja karena mereka memperoleh perlakuan yang adil.

Sedangkan bagi perusahan hasil prestasi kerja pada karyawan sangat penting arti dan peranannya dalam pengambilan keputusan tentang berbagai hal seperti : Identifikasi kebutuhan program pendidikan dan pelatihan, rekrutmen, seleksi, program pengenalan, penempatan, promosi, system imbalan dan berbagai aspek lain dari keseluruhan proses Manajemen sumber daya manusia secara efektif.

Didalam sebuah perusahaan, baik itu perusahaan besar, menengah maupun kecil serta tidak terbatas apakah itu perusahaan yang bergerak dibidang industri, perdagangan maupun jasa tentu tidak terlepas dari masalah untuk mempertahankan keberhasilan Departemen personalia yang dapat dilihat dari prestasi dan pelaksanaan kerja karyawannya.

Apabila suatu perusahaan yang tidak memahami dan memperhatikan pentingnya prestasi kerja ini maka perusahaan tersebut akan mengalami kesulitan dalam menetapkan baik dan buruknya perkembangan perusahaan, mengetahui apakah perusahaan berjalan mengikuti jalur arah yang ditentukan atau menyimpang dari arahnya. 
Mengingat keberhasilan dalam dunia perbankan, sangat ditetapkan oleh sumber daya manusia, maka diperlukan ketangguhan Sumber daya manusia untuk memperoleh sumber daya manusia yang handal sangat bergantung pada penarikan dan pelatihan yang diberikan. Faktor kepuasan kerja sangat dominan untuk produktivitas kerja dari karyawan sehingga hal ini kerja terus mendapat perhatian.

\section{Kajian Literatur}

Pertama perlu pemahaman mengenai kepuasan kerja, menurut Handoko (1992) adalah keadaan emosional yang menyenangkan atau tidak menyenangkan dengan mana karyawan memandang pekerjaan mereka. Menurut As'ad (1995) kepuasan kerja merupakan hal yang bersifat individual, dimana setiap individual akan memiliki tingkat kepuuasan yang berbeda beda sesuai dengan nilai yang berlaku pada dirinya. Kedua, dipahami mengenai teori kepuasan kerja, Gerald Greenberg dan Baron (1995) mengatakan bahwa penyebab kepuasan kerja ada determinan organisasional yang terdiri dari reward system, perceived quality of supervision, work and social stimulation, pleasant working condition, dan determinan lainnya yang bersifat pribadi yaituu personality, job congreaunt with interest, status and seniority, general life satisfaction.

Wexly dan Yukl (1992) menyebutkan kepuasan kerja dibagian dalam teori ketidak sesaian, teori keadilan, teori dua faktor. Menurut Burt Horald E yang dikutip As'ad (1998) faktor yang dapat menimbulkan kepuasan kerja adalah :

1. Faktor hubungan antara karyawan

2. Faktor individual

3. Faktor-faktor luar (Ektern)

Giselli dan Brown mengemukakan adanya factor yang menimbulkan kepuasan kerja, yang dikutip As'ad (1992) menyangkut:

1. Kedudukan

2. Pangkat

3. Umur

4. Jaminan finansial dan jaminan sosial

5. Mutu pengawasan

Menurut Blum sebagaimana dikutip dari As'ad (1992) faktor-faktor penentu kepuasan kerja meliputi :

1. Faktor individual

2. Faktor sosial

3. Faktor utama

Sedangkan penelitian Caugemi dan Claypool yang dikutip As'ad (1992) mengemukakan yang menyebabkan rasa puas adalah :
1. Prestasi
2. Penghargaan
3. Kenaikan pangkat
4. Pujian

Sedangkan faktor yang menyebabkan ketidak puasan kerja adalah :

1. Kebijaksanaan perusahaan

2. Supervisor

3. Kondisi kerja 


\section{Gaji}

Ketiga, perlu pemahaman mengenai prestasi kerja. Menurut Swasto (1996) prestasi kerja adalah tindakan-tindakan atau pelaksanaan tugas yang telah diselesaikan seseorang dalam kurun waktu tertentu dan dapat diukur. Hasibuan (2000) berpendapat bahwa prestasi kerja adalah suatu hasil kerja yang dicapai seseorang dalam melaksanakan tugas-tugas yang dibebankan kepadanya yang berdasarkan atas kecakapan, pengalaman dan kesungguhan serta waktu. Gibson, Evansevich dan Donnelly (1996) secara singkat mengemukakan bahwa prestasi kerja merupakan hasil yang diinginkan dari pelaku.

Dharma (1995) mengemukakan pengukuran prestasi kerja hendaknya mempertimbangkan:

1. Kuantitas, yaitu jumlah yang harus dihasilkan

2. Kualitas, yaitu mutu yang dihasilkan

3. Waktu yaitu kesesuaian dengan waktu yang direncanakan.

Bernandin dan Russel (1995) mengajukan criteria yang dapat digunakan untuk mengukur kinerja yaitu quality, quantity, time lines, cost effectiveness, need for supervision dan interpersonal impact. Mangkunegara (2000) kinerja adalah hasil kerja secara kualitas dan kuantitas yang dicapai oleh seorang pegawai dalam melaksanakan tugasnya sesuai dengan tanggung jawab yang diberikan kepadanya.

Keempat, perlu dipahami mengenai penilaian prestasi kerja. Hasibuan (2000) Penilaian prestasi adalah kegiatan manajer untuk mengevaluasi perilaku prestasi kerja karyawan serta menetapkan kebijaksanaan selanjutnya. Menurut Abdre F Sikula yang dikutif Hasibuan (2000) penilaian prestasi kerja adalah evaluasi yang sistematis terhadap pekerjaan yang telah dilakukan oleh karyawan dan ditujukan untuk pengembangan. Menurut Dale Yoder yang dikutip Hasibuan (2000) penilaian prestasi kerja adalah prosedur yang formal dilakukan didalam organisasi untuk mengevaluasi pegawai dan sumbangan serta kepentingan bagi pegawai.

Rao (1996) penilaian prestasi kerja adalah sebuah mekanisme untuk memastikan bahwa orang-orang pada tiap tingkatan mengerjakan tugas tugas menurut cara-cara yang diinginkan oleh majikan. Siagian (1997), system penilaian prestasi karyawan adalah pendekatan dalam melakukan penilaian prestasi kerja para karyawan dimana terdapat factor yang dinilai, ada tolak ukur yang dikembangkan, ada hasil penilaian dilakukan secara berkala. Hasil penilaian untuk jenjang karier karyawan. Handoko (1985) berpendapat bahwa penilaian prestasi kerja bermanfaat untuk :

1. Perbaikan prestasi

2. Penyesuaian kompensasi

3. Keputusan penempatan

Kelima, persiapan dan pelaksanaan penilaian prestasi kerja diperlukan. Siagian (1997) berpendapat bahwa kematangan hal ini tergantung pada keterkaitan langsungdengan pekerjaan, system yang praktis, kejelasan standard an adanya takaran yang objektif. Handoko (1985) memberikan bias penilai yang terjadi pada hallo effect, kesalahan kecendrungan terpusat, bias terlalu lunak dan terlalu keras, prasangka pribadi, pengaruh kesan terakhir.

Hadipoerwono (1979) berpendapat bahwa dalam pelaksanaan penilaian prestasi harus melihat:

1. Siapa yang bertindak sebagai penilai

2. Waktu penelitian

3. Tempat diolahnya penilaian prestati kerja.

4. Hak penyanggah

5. Sifat rahasia 
Keenam, pentingnya penilaian prestasi kerja dan metode yang digunakan. Soediddjo Notoatmojo (1998) berpendapat penilaian prestasi kerja dalam rangka pengembangan Sumber Daya Manusia sangat penting artinya, dengan memperhatikan asumsi yang digunakan organisasi. Adapun metode penilaian prestasi kerja menurut Soedidjo Notoatmojo (1998) meliputi orientasi waktu lalu (rating scale, check list, peristiwa kritis, peninjauan lapangan, tes prestasi kerja) dan orientasi waktu akan datang ( penilaian diri,MBO,Psikologis, teknik pusat penilaian.

Ketujuh, perlu dipahami hubungan kepuasan kerja dengan prestasi kerja menurut swasto (1996:37) prestasi kerja adalah merupakan tindakan-tindakan atau pelaksanaan tugas yang telah diselesaikan seseorang dalam kurun waktu tertentu dan dapat diukur.

\section{Metode Penelitian}

Menurut Suharsimi Arikunto (1992:102) menyebutkan bahwa populasi adalah keseluruhan subjek penelitian. Sampel adalah sebagian dari populasi yang diteliti. Menurut pemikiran Arikunto (1992) bahwa meneliti sebagian dari populasi diharapkan menggambarkan populasinya lewat pengambilan sampel, dimana apabila populasi diatas 100 maka sample diambil 10-15\% tapi kalau kurang dari 100 maka diambil semuanya. Jadi sample diambil 42 orang. Data yang digunakan dalam penelitian ini bersifat kualitatif dan kuantitatif, dimana pengambilan data melalui teknik studi pustaka, penelitian lapangan seperti wawancara, observasi, documenter, kuesioner.

\section{Hasil Penelitian}

Hasil pengumpulan data menunjukan bahwa dari data responden yang terkumpul sebanyak 42 orang dapat dibuat frekuensi dalam tabel 1.

\section{Tabel 1. Karakteristik Responden Penelitian}

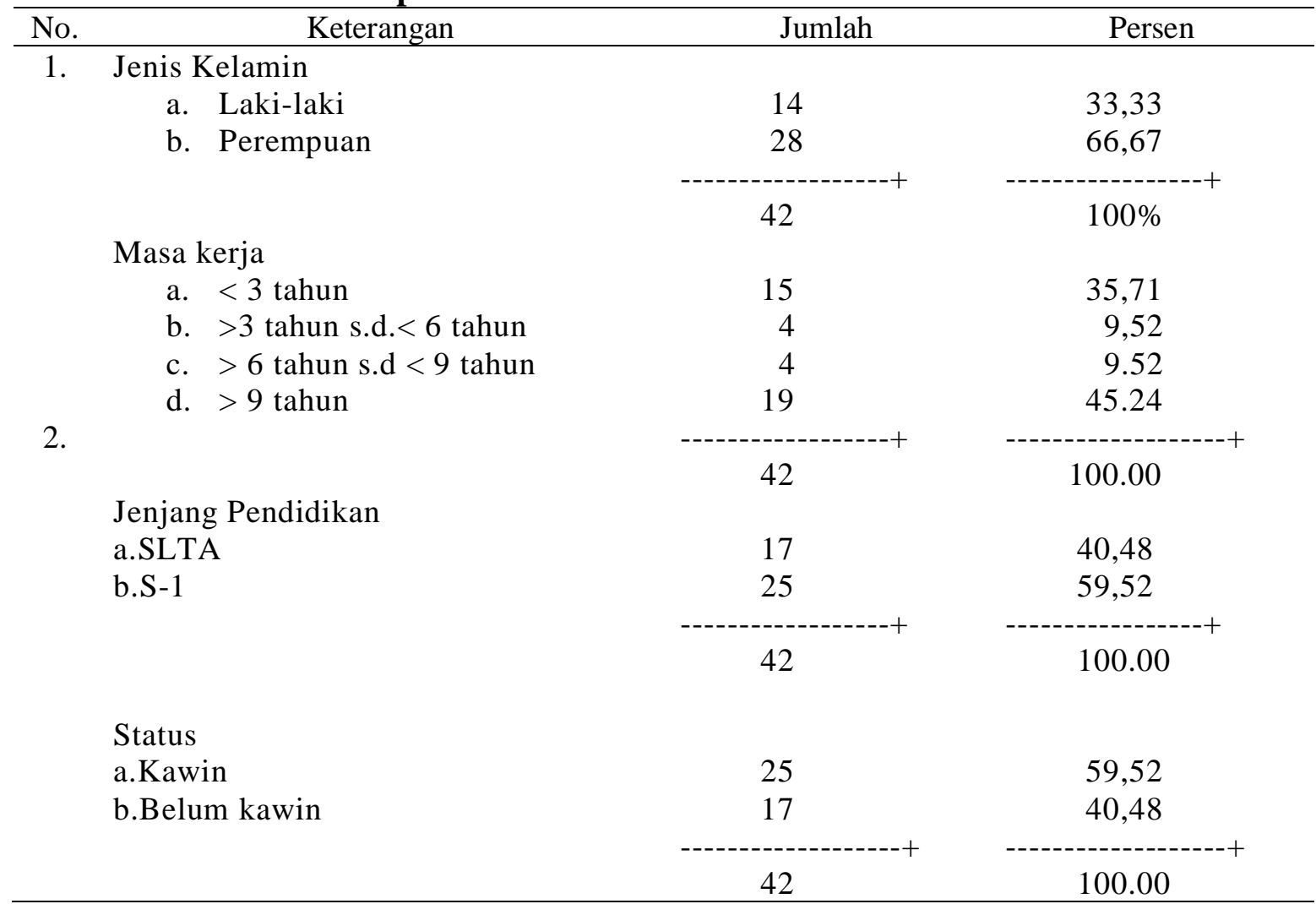


Berdasarkan isi diatas, ternyata sebagian besar responden yang memberikan tanggapan atas pertimbangan factor finansial memiliki jenis kelamin laki-laki 33,33\% sedangkan yang berjenis kelamin perempuan $66,67 \%$. Ditinjau dari masa kerja karyawan yang dipilih sebagai responden sebagian besar sama atau diatas 9 tahun, sedangkan sisanya yang ada memiliki masa kerja diatas 3 tahun.

Adapun jenjang pendidikan formal yang dimiliki responden yang telah memberikan tanggapan atas factor yang diteliti sebagian besar telah tamat perguruan tinggi (S1, sedangkan sisanya tamat Sekolah Lanjutan Tingkat Atas (SLTA). Ternyata sebagian besar responden yang memberikan tanggapan atas faktor Finansial terkait dengan frestasi kerja telah memiliki status perkawinan, yakni sudah kawin 59,52\%, dan yang belum kawin hanya 40,48\% .

Ternyata berdasarkan hasil olah data melalui SPSS ternyata uji t factor finansial memiliki level signifikan dengan $\mathrm{Y}$ dibawah 0,05 dan ditemukan t hitung dengan level signifikan sebesar 0,0299. Dengan demikian dapatlah dikatakan bahwa faktor finansial memiliki hubungan yang signifikan dengan prestasi kerja.

\section{Kesimpulan dan Keterbatasan Penelitian}

Bahwa terdapat hubungan yang signifikan antara faktor finansial dengan prestasi kerja karyawan bank kalsel. Ini artinya, kinerja karyawan Bank Kalsel memang memiliki keterkaitan dengan faktor-faktor finansial. Kedepannya penelitian ini bisa dikembangkan lagi dengan cara mencari pengaruh dari faktor finansial terhadap prestasi kerja karyawan.

Berdasarkan pada hasil penelitian ini, dapat dikemukakan beberapa saran sebagai berikut:

1. Bahwa faktor finansial harus mendapat perhatian serius dari pihak instansi atau kantor bank kalsel.

2. Dilakukan evaluasi prestasi kerja karyawan secara berkala untuk memelihara kinerja organisasi.

\section{DAFTAR PUSTAKA}

Arikunto, Suharsini (1991), Prosedur penelitian suatu pendekatan praktek, cetakan ketujuh, penerbit Rineka Cipta Jakarta.

As'ad 2000, Physiologi industry, Liberty, Yokjakarta.

Dharma, Agus, 1995, Manajemen Prestasi kerja, Rajawali Jakarta. Davis, 1994, Managing colporate coltour Cambridge, Bettenger

Gibson, 1994, Organisasi dan Manajemen, perilaku struktur dan proses, edisi ke empat, Airlangga, Jakarta.

Handoko T Hani, 2001, Manajemen, edisi 2, cetakan ketujuh belas, BPFE Yokjakarta.

Hasibuan 1994, MSDM, Dasar dan kunci keberhasilan, CV. Masagung Jakarta.

Heneman, 1991, Managing personal and Human Resources startegis and problem Dowjpnes Irwin illions.

Lopez, 1992, A test of the self consisten of the job performance job satisfaction Relationship Akademyk of manajement journal Vol 25 No.2.

Martoyo, 1994, MSDM, edisi 3 cetakan pertama, BPFE, Jakarta

M.Zaid Abdurrakhman, 2002, Pengaruh factor-faktor kepuasan kerja terhadap Prestasi kerja Karyawan Bank BPD Kalimantan Selatan.

Robbins, 1990 Perilaku Organisasi, konsep kontroversi alih bahasa, PT. Prelalindo Jakarta.

Siagian P Sondang, (2001), Manajemen Sumber Daya Manusia, cetakan kesembilan belas, Bumi Aksara Jakarta.

Stoner, 1999, Manajemen, Edisi Indonesia Alih bahasa, Alexander Sidoro, PT. Prelalindo, Jakarta. 